\title{
The problem of personality formation: identity, identification, Other (conceptual approaches G.G. Shpet, M.M. Bakhtin)
}

\author{
Evgeny Nesmeyanov $^{1 *}$, and Galina Kharlamova $^{1}$ \\ ${ }^{1}$ Don State Technical University, Department of Philosophy and World Religions, 344000 \\ Rostov-on-Don, Russian Federation
}

\begin{abstract}
The article shows the peculiarities of the Russian philosophy consideration of the theme of identity, identification, formation of personality. The constructive nature of the research of this topic by Russian thinkers in the context of understanding of man as a unique being who seeks to build himself in accordance with the chosen ideal is noted. It is emphasized that identity is achieved through the awareness of the person of his destiny, understanding of the direct experiences of his own experience, creativity, leading to the acquisition of spirituality. It is noted that the approaches of Shpet, Bakhtin allow us to raise the question of a detailed consideration of ways of self-identification of a person, defining the ways of his formation as a person (through a word, act, sympathetic understanding, dialogue, communication with Others). The act of cognition is considered as a Dialogic process conditioned by the unity, participation, participation of consciousnesses. The approach is proposed based on the ideas born in Russian philosophy, according to which personal development can be interpreted as a process of human identification, identity acquisition, identification of a person as a spiritually integral being, comprehending its uniqueness in the context of culture, in the space of communication with Others.
\end{abstract}

\section{Introduction}

Strengthening in modern culture of trends of nonlinear dynamics, the presence of bifurcation points (from lat. bifurcus "bifurcus"), the danger of various qualitative rearrangements, metamorphoses of various objects, changes in the parameters on which they depend, lead to the loss of stability of the existing trends. There is a possibility of branching in the direction of social processes, the dynamics of systems. Nonlinearity, turbulence, predisposition of systems to risk, synergistic effects have been observed not

\footnotetext{
* Corresponding author: harlamova.alina@mail.ru
} 
only in nature but also in society [1]. Anomie, anarchy, apathy become trends, in the light of which the topics related to the processes of personality formation become especially significant. In conditions when a person loses confidence in his abilities, doubts that he is the source, the center of events that can comprehend, explain, control what is happening to him, the question of human identity is actualized. It is put theoretically, solved practically in the context of other problems: "what is" I " as a person?", "What makes a man what he is?", "What are the ways of gaining experience that contributes to the improvement of man, his personal growth" [2].

Many recent theoretical studies devoted to the formation of man as a person, the search for factors and mechanisms that cause them, use the term identification. Thus, in psychoanalysis personality is interpreted as a result of the action of mental, sexual factors. What happens in this process is characterized as identification (from late lat. identif'icoidentify, the term introduced by Freud). Under the identification understand the model of relationship between the child and parents, determining his personal development. Sociologists, like psychologists, consider identification as a process of emotional and other self-identification of an individual, both with another person and a group, a model. Identity is what a person acquires in the process of identification. As a means of its implementation called imitation, imitative behavior, awareness of belonging to a particular community.

The increasing desire in modern culture to put under control the personal development of man, the process of his identification, self-identification contributed to the spread in psychological science of human development studies using statistical methods [3]. Modeling methods have gained popularity. In particular, three-dimensional models are created using the technique of spline modeling (from the English. spline is a flexible curve, flexible plazova rail- a strip of metal used as a template for drawing curved lines). The model constructed by means of splines (three-dimensional curves) represents the spline framework perceived as graphic reflection of changes in personal development of the person. The purpose of such experiments is to assess the maximum possible number of factors affecting human development, to generalize observations of the dynamics of the development of one or many people over a long time. The results of such studies are accepted as a platform for the development of corrective techniques. With their help, according to the researchers, it is possible to neutralize the problems of education that arise during the transition of a person from one age stage of development to another, to minimize the difficulties of identification at each stage $[4 ; 5]$.

Marxism, which develops the idea that personal development is conditioned by the class affiliation of the subject, is presented in the modern scientific picture of the world along with the concepts of feminists. Feminism connects the formation of personality, the acquisition of identity by a person with his gender role, and admits that the forms of personal behavior are determined (dictated, imposed) by gender stereotypes constructed in society. Studies in the field of transgender identity also speak about the possibility to dictate stereotypes. The condition for the possibility of countering such practices, according to scientists, may be the awareness of a person's gender identity. Referring to court decisions, ethnographic observations, interviews, researchers reveal the nature of non-traditional orientations. In particular, they are able to identify the reasons for the recognition of such a sociotype as transgender, to explain its existence in society by the presence of a genetically determined phenomenon of sex suppleness. In explicit or implicit form, it also serves as a prerequisite for the emergence at the theoretical level of binary concepts of sex. Awareness in this area allows a person to be aware of gender identity. As a result, according to the authors of the idea, the citizen acquires the ability to protect himself in the conditions of social practice of introducing gender stereotypes into the human consciousness [6].

However, in the study of the problem of identity there are difficulties to overcome which are not fully used the possibilities of philosophical anthropology. Aiming at an 
interdisciplinary approach in understanding the problems of personal development of man, his identity and identification, the principles of philosophical anthropology define a broad socio-cultural context of the problem, open the possibility of its solution in connection with the answer to the question: "what is a man". The above contributed to the definition of the purpose of the article-based on the ideas of Russian thinkers, to explore the processes that clarify the nature of identity, its essential characteristics; to clarify the value of identification in human life, the role of the Other in the processes of identification of man, his personal development.

\section{Findings}

Identification of the relationship between the concepts of personal development and identity is based on such meanings of the term identity as identification, recognition, assimilation, sameness. Personality is characterized as a person who is responsible for the outside world, other people, himself. He is able to determine his own trajectory of life, to become purposeful, independent, dynamic, holistic, constructive, preserving individuality. In the late twentieth century. according to its semantic load, identity and identification are close to the concepts of "personality", "self", "subjectivity", individuality, originality, distinctive feature, which is vividly represented in the national philosophy. The theme of identity, identification is revealed by Russian thinkers in the context of the idea of uniqueness (uniqueness) of man. His desire to build himself in accordance with the chosen ideal is interpreted as an essential quality that determines the destiny of man. Life orientations are associated with the awareness of direct experiences of their own experience, creativity, spirituality. Such benchmarks can serve as a criterion for the identification of a person as a person. Identification is associated with knowledge, involving a person as a whole. This type of knowledge is carried out in the conditions of moral communication of individuals. It does not imply the distinction of people on the principle of "objects and subjects of interaction." Based on G.G. Shpet's methodological experience, the modern researcher is obliged to take into account such human capabilities as understanding, discretion, understanding. They also accompany his self-knowledge, which determines the success of the search for identity. The philosopher broadens the understanding of the nature of identification, identity, offering all the problems of personal development to discuss in the framework of the concept of human uniqueness [7]. It is necessary to remember the basic the person, being included in community, possesses the place where nobody can replace it. Man's pursuit of his destiny makes man free, but it is carried out within the limits determined by himself and other people acting in accordance with their own destiny. The similarity of people is that each of them is unique, and they are all different. Shpet's approach aims at a detailed consideration of ways of self-identification of a person, his formation as a person. The main of them are language, word. The word acts as a carrier of thoughts, feelings, means of communication. It is an act of social and cultural consciousness, a form of its embodiment [8]. Perceiving words, a person activates the ability to comprehend heard, read, penetrate into the essence of consciousness-not only to see the deep meanings, but also to master them. Discretion, understood as the grasping of meaning and the essential characteristic of consciousness, involves the penetration of knowledge of explicit and implicit premises. It performs the function of addressing prelogical, pre-conceptual - in General, pre-reflexive-forms and components of consciousness. Discretion determines the possibility of subsequent explication, interpretation of the perceived.

M.M. Bakhtin also developed the theme of the uniqueness of a person as a person associated with the problems of identity and identification, personal formation. Man as such differs emotionally-strong-willed originality. The character of his participation in being is 
unique already at the level of action. The being that forms around him as the Only being also acquires unique features, since it is determined by an act, committed by a specific, unique person. Bakhtin considers this thesis an axiom [9].

Introducing the concept of sympathetic understanding, M. M. Bakhtin sought to emphasize that the subject and the object are one, a specific indivisible community. But the emerging community also presupposes the dissimilarity of personalities, i.e. substantial unity between them is impossible.

M.M. Bakhtin, like G.G. Shpet, sees in the process of cognition the condition of the possibility of becoming a spiritually integral person. The meaning of his philosophy is to warn people against actions that will result in the formation of a one-sided epistemological subject. The philosopher emphasizes the idea that knowledge should contribute to the achievement of human integrity, due to the completeness of the manifestation of his personal powers. The act of cognition, from the point of view of the thinker, should be considered as a dialogical process, involving unity, participation, participation of consciousnesses. It determines the involvement of all human capabilities. The philosopher characterizes the process of cognition as a space of joint activity, where there is a special communication that contributes to the formation of a person as an integral being, as a person.

Personal development, therefore, comprehended by M.M. Bakhtin as a process aimed at the identification (identity) of oneself as spiritually holistic beings. The recognition of oneself as a spiritually integral being is the result, the consequence of the person's selfidentification, the source of which is connected with the understanding of his uniqueness in the space of culture. Identification, self-identification become possible in the space of communication with Others in the process of creating the world as the human world. Feature of creative activity of the person is its maintenance by acts of assignment to objects of names, names. This kind of human activity, characterized as incarnation, humanization, M.M. Bakhtin called incarnation. Incarnation, humanization, incarnation, in fact, means identification, contributing to the self-development of man, his becoming a spiritually integral man in the space of communication with Others.

\section{Method of research}

The principles of phenomenology contributed to the study of the processes clarifying the nature of identity, its essential characteristics, revealing the significance of identification in human life, determining the role of the Other in the processes of human self-identification and personal development. They Orient the researcher to the study of identity, identification, attracting the concept of intentionality-the orientation of consciousness to the object. Intentionality emphasizes the aspiration of thought to the object, denotes the presence of a living (immediate) connection between man and the world, directs the researcher-philosopher to study the experiences of man, namely what can be described (lat. describere-to describe), but not subject to definition (lat. definitio) - strictly logical operation, not fully revealing the content of human States.

The phenomenological method helps to understand the conditionality of the process of personality formation by the fact of the initial presence of a person in the life world. The concept of the life world denotes everything that is fundamentally accessible to contemplation, and allows us to restore its semantic Foundation forgotten by natural science [10].

Hermeneutics, associated with the art of interpretation, theory of interpretation and understanding of texts, complements the phenomenological approach. Its fruitfulness is found in the works of Russian thinkers who studied the role of such forms of human activity as understanding, explanation, discretion, understanding. The latter accompany 
human self-knowledge, determine the processes of identification and self-identification. As a methodological device, which is absent in the Arsenal of natural Sciences, hermeneutics allows us to consider the transition from the sign to the meaning not as a conclusion, but as a direct act of discretion of the meaning. The meaning is considered as a reasonable, essential basis. In the light of this methodology, identity and the processes of its achievement (identification, self-identification) can be interpreted as phenomena, the essence of which predetermines the formation of a person as a person.

The methodology of philosophical anthropology helps to identify the essential features of identity by considering it in the broad context of the processes that determine the formation of man at the stage of his transition "from the realm of necessity to the realm of freedom", entering the world of culture created by him and his predecessors. Within the framework of this philosophical orientation, identity presupposes the process of selfidentification of a person. It accompanies his formation as a person from the very beginning of the movement in the historical space, is associated with the installation: "Know yourself", formulated by ancient thinkers [11].

\section{Conclusion}

The conceptual approaches of G.G. Shpet and M.M. Bakhtin contribute to clarifying the nature of identity and revealing its essential characteristics. Identity as a concept emphasizes the inclusion of a person in the connection of the world - the world of nature, things, people (Others). Identity can be interpreted as a set of human qualities that allow to identify him (her) as a subject of culture, society, as a person. Philosophers expand the understanding of the nature of identification, identity, offering all the problems of personal development to discuss in the light of the idea of human uniqueness. G.G. Shpet's methodological experience serves as the basis for consideration of such human capabilities as understanding, discretion, understanding. They accompany his self-knowledge, which expands the space of understanding the specifics of ways of self-identification.

Identity is possible through identification through words, actions, dialogue. A necessary condition should be moral communication, understood as communication that does not provide for the division of people into objects and subjects of interaction.

The ideas of Russian philosophers allow to interpret identification as a process of achieving identity. Due to hermeneutic acts, the process of identification, involving such forms of human activity as understanding, explanation, helps to identify the deep meanings of human life, their subsequent interpretation (interpretation). Having significantly supplemented phenomenology with hermeneutics, Russian thinkers prepared the grounds for an expanded interpretation of identification as a process of formation of a person's identity, considering it as a factor of personal growth. The ideas of Russian philosophers open the direction of studying the ways of identification, leveling the boundaries established by natural science between the Self and the thing, the Self and Others. Identity, identification in a person's life is determined by the participation of Others. The views of Russian thinkers are particularly significant as a paradigm of research on the human situation in modern globalized societies. They are important for the development of recommendations that contribute to the maintenance of human integrity, sustainable mental existence, achieving social fullness. The ideas of Russian thinkers support in-depth consideration of the thesis that the identity of a person, his personal development unfolds in culture. Culture functions through the interaction of two forms of its existence - objective and subjective. Both sides provide its own identity, determine its self-preservation and normative-value, semantic identity. The special importance of the principle of identity for the cultural self-determination of man and society was recognized by such a supranational organization as UNESCO. 
Identity can be characterized not only as the core of human existence, but also as the vital core of culture. It acquires the meaning of a dynamic principle by which, based on the past, man and culture use their inner potential, carry out a process of continuous development.

\section{References}

1. N. N. Fedotova, Knowledge. Understanding. Ability, 2, 52-62 (2013)

2. E.E. Nesmeyanov, G.S. Kharlamova, Y.T. Isaeva, N.A. Malishevskaya, V.G. Tahtamishev, MJLTM, 9, (2018)

3. S. Nestler, S. Humberg, D. Felix, Psychological Methods, 24, 291-308 (2019)

4. H.W. Suk, S.G. West; K.L, Fine, K.J. Grimm, Psychological Methods, 24, 269290 (2019)

5. S.S. Driver, C. Voelkle, Psychological Methods, 23, 774-799 (2018)

6. S. Vogler, Gender \& Society, 33, 439-462 (2019)

7. G.G. Shpet, Philosophical etudes (Progress, Moscow, 1994)

8. G.G. Shpet, Works (Pravda, Moscow, 1989)

9. M.M. Bakhtin, Works of the 1920s (Next, Kyiv, 1994)

10. E. Husserl, Logical studies. Cartesian meditations. Crisis of European Sciences and transcendental phenomenology. The crisis of European humanity and philosophy. Philosophy as a strict science (ACT, Moscow , 2000)

11. K.A. Swassjan, the Man in the maze of identities (Evidentis, Moscow, 2009) 